\title{
Changes in the interannual variability of the tropical Pacific as a response to an equatorial Atlantic forcing
}

\author{
MARTA MARTÍN-REY ${ }^{1,2}$, IRENE POLO ${ }^{3}$, BELÉN RODRÍGUEZ-FONSECA ${ }^{1,2}$ \\ and FRED KUCHARSKI ${ }^{4}$ \\ ${ }^{1}$ Instituto de Geociencias, CSIC-UCM, Facultad de Ciencias Físicas, 28040 Madrid, Spain. \\ E-mail: mmartindelrey@ fis.ucm.es \\ ${ }^{2}$ Universidad Complutense Madrid, Departamento de Física de la Tierra Astronomía y Astrofísica I, 28040 Madrid, Spain. \\ ${ }^{3}$ NCAS-Climate, University of Reading, Reading, United Kingdom. \\ ${ }^{4}$ Abdus Salam International Centre for Theorical Physics (ICTP), Earth System Physics Section, Trieste, Italy.
}

SUMMARY: Previous studies have reported that the tropical Atlantic has had an influence on tropical Pacific interannual variability since the 1970s. This variability is studied in the present work, using simulations from a coupled model in the Indo-Pacific but with observed sea surface temperature (SST) prescribed over the Atlantic. The interannual variability is compared with that from a control simulation in which climatological SSTs are prescribed over the Atlantic. Differences in the Pacific mean state and in its variability are found in the forced simulation as a response to a warming in the equatorial Atlantic, characterized by a cooler background state and an increase in the variability over the tropical Pacific. A striking result is that the principal modes of tropical Pacific SST interannual variability show significant differences before and after the 1970s, providing new evidence of the Atlantic influence on the Pacific Ocean. Significant cooling (warming) in the equatorial Atlantic could have caused anomalous winds in the central-easter Pacific during the summer since 1970s. The thermocline depth also seems to be altered, triggering the dynamical processes involved in the development of El Niño (La Niña) phenomenon in the following winter. An increase in frequency of Niño and Niña events favouring the Central Pacific (CP) ones is observed in the last three decades. Further analyses using coupled models are still necessary to help us to understand the causes of this inter-basin connection.

Keywords: Tropical Atlantic variability, Atlantic-Pacific connection, ENSO.

Resumen: Cambios en la variabilidad interanual del Pacífico Tropical como respuesta a un forzamiento del AtLÁntico Ecuatorial. - Trabajos previos han puesto de manifiesto como el Atlántico Tropical influye en la variabilidad interanual del Pacífico a partir de los años 70. El presente trabajo estudia la variabilidad del Pacífico Tropical a partir de simulaciones realizadas con un modelo acoplado en el Indo-Pacífico que considera la Temperatura de la Superficie del Mar (TSM) observada en el Atlántico como forzamiento externo. Los resultados de esta simulación son comparados con los obtenidos en una simulación de control, con TSM climatológicas en el Atlántico. La simulación forzada muestra cambios en el estado base y la variabilidad del Océano Pacífico relacionados con un calentamiento en el Atlántico ecuatorial, destacando un aumento de la variabilidad y un enfriamiento del Pacífico ecuatorial. Además, los principales modos de variabilidad del Pacífico antes y después de los 70 son diferentes, reafirmándose la influencia del Atlántico sobre el Océano Pacífico. Un enfriamiento (calentamiento) en el Atlántico ecuatorial podría generar vientos anómalos en el centro-este de la cuenca del Pacífico durante el verano desde dicha década. La profundidad de la termoclina también se modificaría, desencadenándose los procesos dinámicos involucrados en el desarrollo de El Niño (La Niña) en el invierno siguiente. Los resultados muestran un aumento de la frecuencia de Niños y Niñas, favoreciéndose los eventos del Centro del Pacífico (CP) en las últimas décadas. Estudios adicionales mediante el uso de modelos acoplados serían necesarios para poder comprender las causas de la conexión entre cuencas.

Palabras clave: variabilidad del Atlántico Tropical, conexión Atlántico-Pacífico, ENSO. 


\section{INTRODUCTION}

Atlantic and Pacific Tropical basins have similar interannual variability modes referred to as the Atlantic Niño and El Niño-Southern Oscillation (ENSO), peaking in the boreal summer and winter respectively. Both of them are characterized by an anomalous warming in the east of the basin, associated with a weakening of the climatological trades and supported by the Bjerknes positive feedback (Bjerknes 1969, Zebiak 1993). Although ENSO impacts are larger, both are known to have worldwide impacts (Philander 1990, Polo et al. 2008, García-Serrano et al. 2008, Losada et al. 2010a,b, López-Parages and Rodríguez-Fonseca 2012).

Previous papers have studied the possible relationship between the Atlantic and Pacific Niños, suggesting a lack of connection (Wang et al. 2006) or a fragile relationship between them (Chiang et al. 2000, Chang et al. 2006). However, recent studies report an increase in the correlation between the Atlantic and Pacific SST interannual variability (Münnich and Neelin 2005, Keenlyside and Latif 2007), highlighting the leadership of the tropical Atlantic in the interbasin connection since the early 1970s (Rodríguez-Fonseca et al. 2009). Several model studies have also suggested the impact of the Atlantic SST on the Pacific basin via atmospheric teleconnections (Dommenget et al. 2006, Sutton and Hodson 2007, Rodriguez-Fonseca et al., 2009; Losada et al. 2010a, Wang et al. 2010).

Recently, Ding et al. (2011) replicated the experiment of Rodríguez-Fonseca et al. (2009) with a more resolved coupled model, finding good agreement between the model and the observations and confirming this leadership of the Atlantic during the last few decades. The former authors claimed that the relationship between basins is stationary, whereas RodríguezFonseca et al. (2009) claim that the relation does not hold before the 1970s.

Significant anti-correlations have been found between the summer (JJAS) Atl3 index and the next winter's (DJFM) Niño3 index since the late 1960s and not before, in observations and modelled data (Fig. 1). These correlations support the result of RodríguezFonseca et al. (2009): a summer Atlantic Niño could favour the development of a Pacific Niña during the next winter. However, the lack of significant correlation between Atl3 and modelled Niño3 in the summer months (Fig. 1) suggests that other processes could be contributing to the development of the thermal anomalies in the Pacific Ocean.

Using the same simulations as Rodríguez-Fonseca et al. (2009), recent studies have tried to characterize the oceanic processes involved in the development of ENSO due to the Atlantic influence in the last few decades (Martín-Rey et al. 2010). Different mechanisms seem to be contributing to the heat balance of the tropical Pacific before and after the 1970s, but further analyses are needed to understand the influence of the Atlantic on the Pacific Ocean.

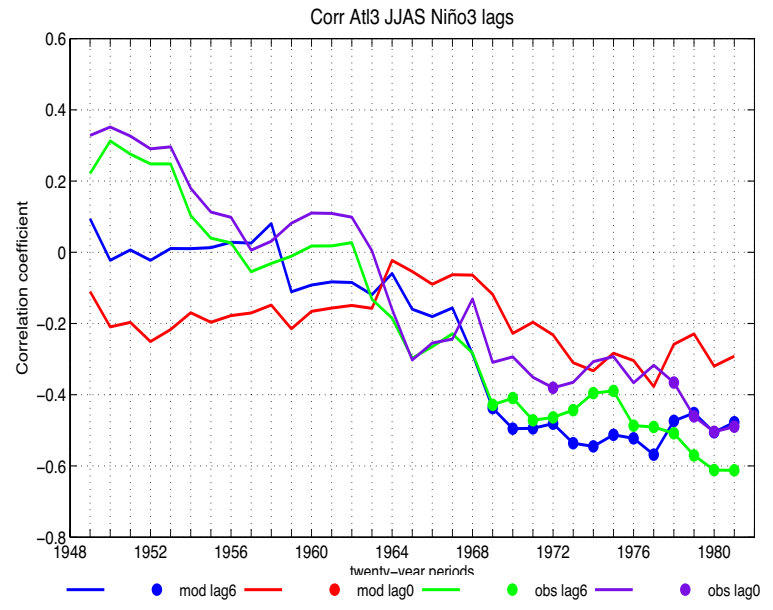

FIG. 1. - Running correlation of 20-year windows, from 19501969 to 1981-2000 between summer (JJAS) observed Atl3 index and Niño3 index in lag 0 (JJAS) and lag +6 (DJFM) from model (SimAtlVar) and observations. A Monte Carlo test has been applied and significant values at $90 \%$ confidence level are represented in dots. The observations come from HadISST1 (Rayner et al. 2003). A colour version of this figure may be found in the online electronic manuscript.

According to previous studies, a remarkable change has taken place in the last few decades, in both the characteristics and development of the ENSO phenomena (An and Wang, 2000, Federov and Philander 2000, An 2008, Choi et al. 2010, Yeh et al. 2011). Alterations of the intensity, frequency and type of the ENSO have also been observed in recent decades (Kao and Yu 2009, Lee and McPhaden 2010). This shift could be associated with changes in the Atlantic (Dong et al. 2006) and/or Pacific background state (Moon et al. 2004), since an alteration of the mean sea surface temperature (SST), thermocline depth (z20) and zonal wind can modify the ENSO characteristics (Federov and Philander 2000). In addition, a "feedback-like mechanism" between the mean state and the interannual events has been documented, so warm (cold) ENSO events seem to increase (decrease) the SST of the equatorial region, changing, in turn, the background state (Kug et al. 2009, Lee and McPhaden 2010).

Regarding the variability of the ENSO phenomenon, several authors have reported the different ENSO "flavours", eastern Pacific (EP) and central Pacific (CP), in the last century, suggesting great differences in their sources and impacts (Kug et al. 2009, Kao and Yu 2009, Yeh et al. 2009, Choi et al. 2010). The origin of the CP and EP ENSO is associated with different forcings, so EP ones are highly dependent on thermocline variations, while $\mathrm{CP}$ ones are mainly influenced by atmospheric forcing (Kug et al. 2009, Choi et al. 2010). Likewise, other studies have shown the importance of the mean state in favouring EP or CP ENSO (Yeh et al. 2009, 2011, Choi et al. 2010, Yeh et al. 2011).

Although previous studies have pointed out the connection between the tropical Atlantic and Pacific Ocean and the leadership of the Atlantic in this connection (Rodríguez-Fonseca et al. 2009, Ding et al. 2011); and others have indicated the modification of 
the oceanic and atmospheric processes involved in the development of the ENSO since the early 1970s (Martín-Rey et al. 2010), changes in the principal modes of variability and in the type, frequency and phase of the ENSO events have not yet been studied. Furthermore, the previous studies were very restricted to Atl3 and Niño3 regions and not to the entire tropical basins

The aim of the present work is to clarify whether the Pacific SST interannual variability has really changed due to the Atlantic Ocean forcing in the last decades of the 20th century. To this end, here we describe the first variability mode for the forced simulation, comparing this mode with that from an unforced simulation in order to isolate the mode due to the Atlantic influence. Two different periods were chosen in order to verify the non-stationary impact of the Atlantic over the Pacific.

The paper is organized as follows: First, the data and methodology are described. Then the main results are presented, focusing on: i) the analysis of the modification of the Pacific variability since the 1970s and the possible alteration of the Pacific and Atlantic mean states; ii) the analysis of changes in the interannual variability of the tropical Pacific due to Atlantic forcing; and iii) classification of ENSO events. Finally, a discussion and the conclusions are presented.

\section{MATERIALS AND METHODS}

\section{Data and model}

This study was carried out using both observed and modelled data. The observational SST came from the HadISST1 (Rayner et al. 2003) dataset of the UK Metoffice (http://hadobs.metoffice.com/hadisst/). The observed wind stress was obtained from the Simple Ocean Data Assimilation (Carton et al. 2000). The modelled SST, thermocline depth and wind stress outputs came from coupled model simulations. The atmospheric component of the model was the ICTP General Circulation Model (Kucharski et al. 2008) version 40, with T30 horizontal resolution and 8 levels in the vertical. The oceanic part was an extended 1.5-layer reduced-gravity model with a resolution of $2^{\circ} \times 1^{\circ}$ longitude-latitude (Chang 1994). Two different groups of simulations were used:

- Fully-coupled simulations in the tropical Indo-Pacific basin and climatological SSTs elsewhere, except for the Atlantic Ocean, where observed monthly varying SSTs were used. The resulting SST for the tropical Pacific basin corresponds to an ensemble of nine runs for the total period 1949-2002 (as in Rodríguez-Fonseca et al. 2009). Hereafter this simulation will be named SimAtlVar.

- Fully-coupled simulations in the tropical Indo-Pacific basin and climatological SSTs elsewhere. The resulting SSTs of the ensemble of five runs corresponded to a total period of 132 years. Hereafter this simulation will be named SimAtlCli.
The ability of the model to reproduce the connection between the interannual events of the Atlantic and Pacific Oceans was demonstrated by Rodríguez-Fonseca et al. (2009). Both the model and the observations show the beginning of this interbasin connection in the late 1960s and the model also confirms the alteration of Walker circulation as the responsible mechanism for this connection in the last few decades.

It is important to analyse the reliability of the model in simulating the equatorial Pacific seasonal cycle and its variability (Fig. 2). The observed seasonal cycle is relatively well captured by the model (solid lines) although the amplitude of the simulated annual mean SSTs is higher than that of the observed ones, exhibiting a warm SST bias in the eastern equatorial Pacific, which is a common feature of most coupled models (Lin et al. 2010, Zhao et al. 2011, Mechoso et al. 1995).

Regarding the standard deviation, the model shows an increase in the variability in the Niño3 region during the summer, coinciding with the maximum variability of the tropical Atlantic (not shown). The Pacific variability peaks in July in both SimAtlCli and SimAtlVar, showing higher values in the latter, which could be associated with Atlantic forcing (Fig. 2). On the other hand, the observations indicate maximum variability of the Niño3 region in winter when this phenomenon peaks (dotted line).

Although it is known that the seasonal cycle of the tropical Pacific is mainly due to internal variability (Xie 1994), the significant differences obtained between the seasonal cycle of SimAtlVar and SimAtlCli (Fig. 2, stars) could be due to the Atlantic influence, because it is the only external forcing. This fact should

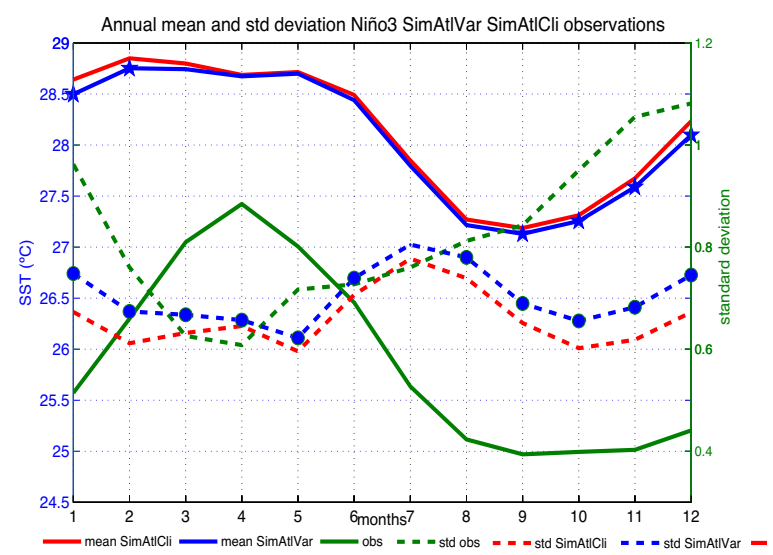

FIG. 2. - Seasonal cycle and standard deviation of Niño3 index from SimAtlVar, SimAtlCli and observations. Solid lines are associated with $\mathrm{y}$-axis on the left (in ${ }^{\circ} \mathrm{C}$ ) and dotted ones with the $y$-axis on the right side. The observations come from HadISST1 (Rayner et al. 2003). The difference between the seasonal cycle and standard deviation from SimAtlVar respect SimAtlCli has been calculated and a t-test of equal means and a F-test have been applied. Significant differences at $95 \%$ confidence level are shown in stars and dots for seasonal cycle and standard deviation respectively over SimAtlVar lines. A colour version of this figure may be found in the online electronic manuscript. 
be also taken into account in the comparison with observations, since the lack of agreement could be associated with other external contributions such as the impact of the Indian Ocean (Izumo et al. 2010) and global warming (Kucharski et al. 2011), not taken into account in the present work.

Three indexes were used in this study to characterize Pacific El Niño, the Atlantic Niño and the western equatorial Atlantic. Niño3 is defined as the SST anomalies averaged over the area $150^{\circ} \mathrm{W}$ to $90^{\circ} \mathrm{W}$ and $5^{\circ} \mathrm{N}$ to $5^{\circ} \mathrm{S}$; Atl 3 index is defined as the SST anomalies averaged over the area $20^{\circ} \mathrm{W}$ to $0^{\circ} \mathrm{E}$ and $3^{\circ} \mathrm{N}$ to $3^{\circ} \mathrm{S}$; finally, Atl4 is defined as the SST anomalies averaged over the area $40^{\circ} \mathrm{W}$ to $20^{\circ} \mathrm{W}$ and $3^{\circ} \mathrm{N}$ to $3^{\circ} \mathrm{S}$.

\section{Methods}

Most of the analyses performed in this study are based on statistical comparisons of both the background state and the variability of the Pacific due to the Atlantic influence before and after the 1970s, considering the seminal work of Rodríguez-Fonseca et al. (2009).

The analyses concerning changes in the background state and decadal variability of the Pacific Ocean include statistical tests of significance. Two different tests were used, a $t$ test and an $F$ test. The $t$ test is a parametric test applied under the equal means null hypothesis. The $F$ test is a two-tailed test that considers the equal variances as the null hypothesis. Significant values at the $90 \%$ and $95 \%$ confidence level are shown in the present study. In the significance tests for the set of simulations in the equatorial Pacific (Figs. 2 and 3), all members of the ensemble were taken into account instead of the ensemble mean.

The analysis related to the determination of modes of SST interannual variability was based on the empirical orthogonal functions (EOF) technique, which was applied to the total period 1949-2002. The EOF analysis (von Storch and Frankignoul 1998) is used to decompose the anomalous field into a number $n$ of modes which maximize the variance of a two-dimensional space-time matrix $Y\left(n_{s}, n_{t}\right)$ being $n_{s}$ the spatial dimension and $n_{t}$ the temporal one. The solution of the eigenvalue problem for the variance matrix

$$
C\left(n_{s}, n_{t}\right)=Y \times Y^{T}
$$

provides $n$ principal eigenvectors, $\operatorname{EOF}\left(n_{s}, n\right)$, and $n$ eigenvalues $\lambda_{n}$, indicating the explained variance for each EOF. These EOFs represent the directions of maximum $Y\left(n_{s}, n_{t}\right)$ variability of the total field. The time series or principal components (PC) associated with these spatial patterns are obtained by projecting the EOF over the initial matrix Y

$$
P C_{k}\left(1, n_{t}\right)=\operatorname{EOF}_{k}^{t}\left(1, n_{s}\right) \times Y\left(n_{s}, n_{t}\right)
$$

where $k$ corresponds to the number associated with each of the eigenvectors, $\mathrm{k}=1, . ., \mathrm{n}$.
In the present study, the monthly SST anomalies from December to March (DJFM) were chosen for the period 1949-2002. In order to isolate interannual variations from those of lower frequencies, the difference between the values of each two consecutive years was computed, giving a new field $\Delta y=y_{k}-y_{k-1}$. This is a standard and widely-used method for filtering time series (Bjerknes 1964, Stephenson et al. 2000). The EOF analysis for the set of simulations takes into account all members of the ensemble instead of the ensemble mean.

To assess the robustness of the results, a Monte Carlo non-parametric significance test was performed. This methodology creates a random distribution of the sample, permuting the original time series and analysing the non-shuffled results with those obtained by chance. Significant values at the $90 \%$ confidence level are shown according to this test.

El Niño types were classified as Eastern Pacific (EP) and Central Pacific (CP) according to the location of the maximum SST, which placed them in Niño3 $\left[150^{\circ} \mathrm{W}\right.$ $\left.90^{\circ} \mathrm{W} ; 5^{\circ} \mathrm{N}-5^{\circ} \mathrm{S}\right]$ or Niño4 $\left[160^{\circ} \mathrm{E}-150 \mathrm{~W}^{\circ}, 5^{\circ} \mathrm{N}-5^{\circ} \mathrm{S}\right]$ regions (Kao and Yu 2009, Kug et al. 2009, Yeh et al. 2009). The ENSO events created by the model show their SST anomalies slightly displaced eastward, so a new definition of Niño3 and Niño4 regions is necessary: Niño $3^{*}\left[140^{\circ} \mathrm{W}-90^{\circ} \mathrm{W} ; 5^{\circ} \mathrm{N}-5^{\circ} \mathrm{S}\right]$ and Niño4* $\left[180^{\circ} \mathrm{E}-120^{\circ} \mathrm{W}, 5^{\circ} \mathrm{N}-5^{\circ} \mathrm{S}\right]$. CP (EP) Niños satisfy the condition $\overline{S S T}_{\text {Niño4* }}>\overline{S S T}_{\text {Niño3* }}\left(\overline{S S T}_{\text {Niño4* }}<\overline{S S T}_{\text {Niño3* }}\right)$. On the other hand, CP (EP) Niñas satisfy the condition $\overline{S S T}_{\text {Niño } 4 *}<\overline{S S T}_{\text {Niño3* }}\left(\overline{S S T}_{\text {Niño4* }}>\overline{S S T}_{\text {Niño } 3 *}\right)$.

\section{RESULTS}

\section{Changes in the mean state and decadal variability}

As stated above, Atl3 interannual variability has been significantly correlated with Niño3 variability since the late 1960s (Fig. 1). Although this result was also shown in Rodríguez-Fonseca et al. (2009), the changes in the background state or climatological mean of the tropical Atlantic and Pacific basins were not discussed in that work. To tackle this problem, alterations in the Pacific and Atlantic mean and standard deviation during the period 1950-2000 were analysed. Figure 2 shows significant differences in the seasonal cycle (stars) and standard deviation (dots) over the eastern Pacific in SimAtlVar in comparison with SimAtlCli.

The mean SST over the eastern Pacific is cooler in winter months for SimAtlVar than for SimAtlCli (Fig. 2 ), while relatively high variability is shown in the forced simulation (dotted lines). A comparison between the simulations forced by the Atlantic and the control simulations suggests that the addition of the Atlantic Ocean seems to cool the Pacific mean SST during the winter and enhance its variability in all seasons.

Using 20-year windows (Fig. 3), the changes in the Pacific mean state during the study period were evaluated by subtracting the total mean of SimAtlCli from each 20-year mean of SimAtlVar. Two months were 
a) dif mean Atl July

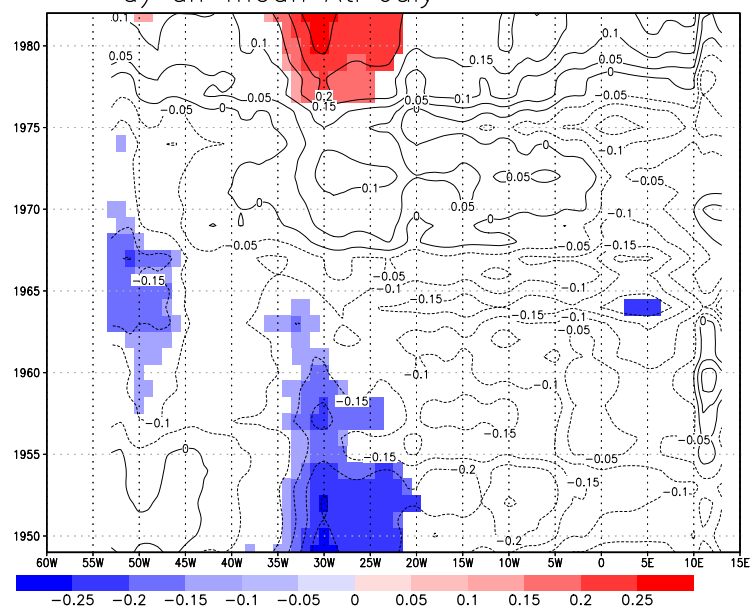

c)
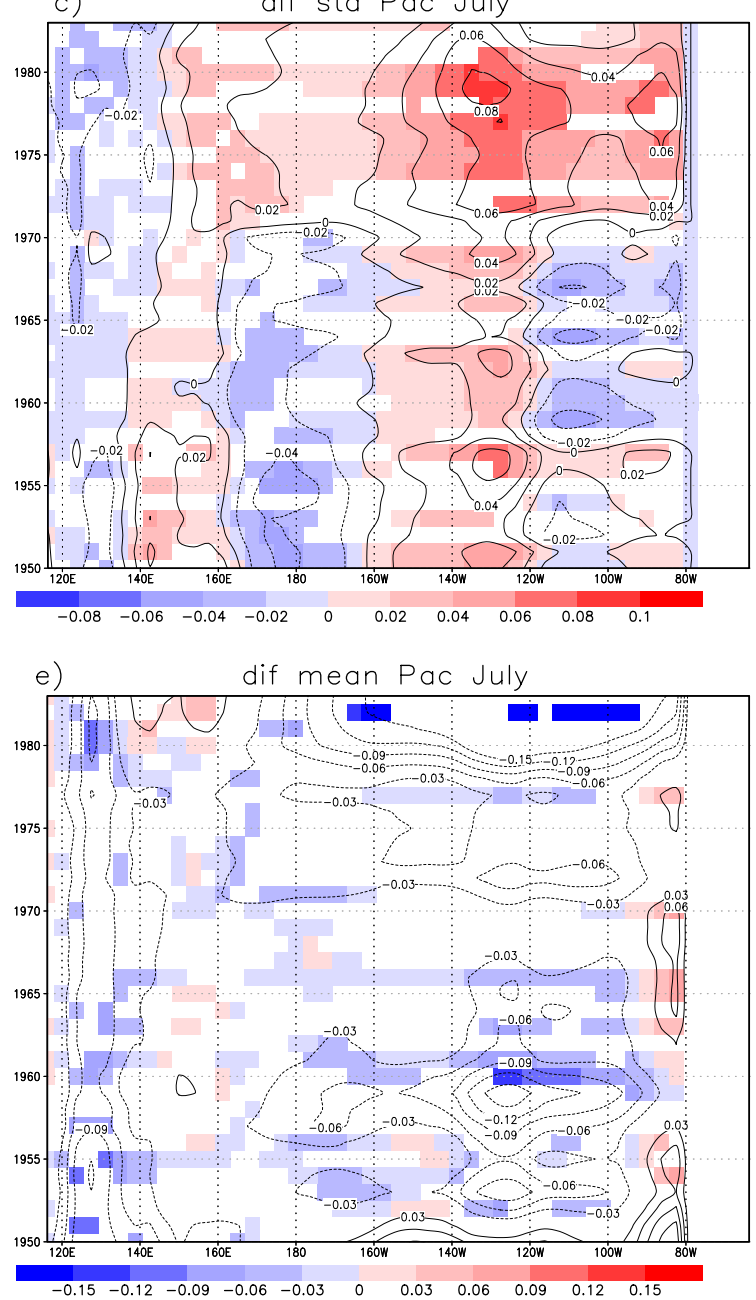

a) dif mean Atl Dec

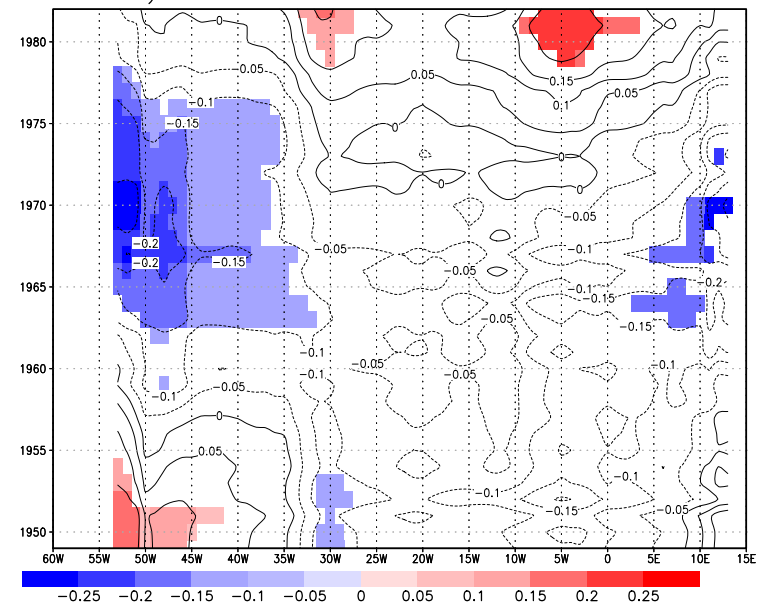

d)

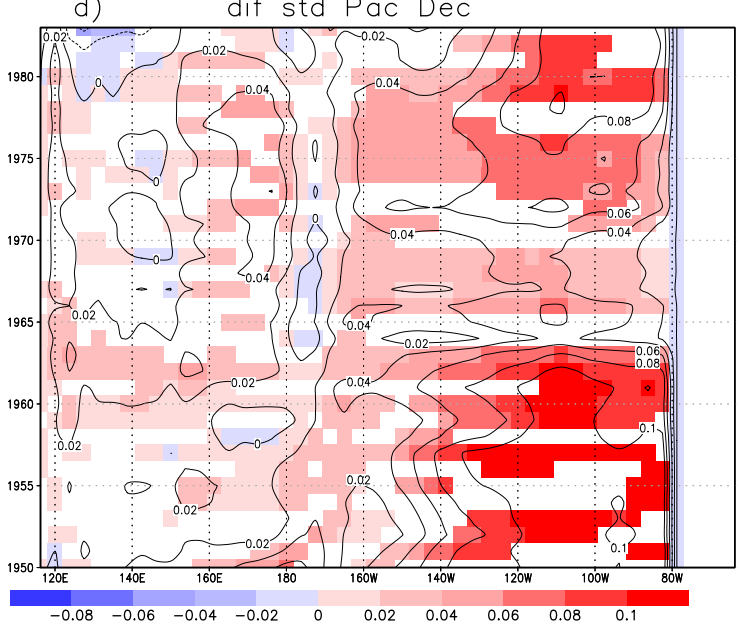

e)

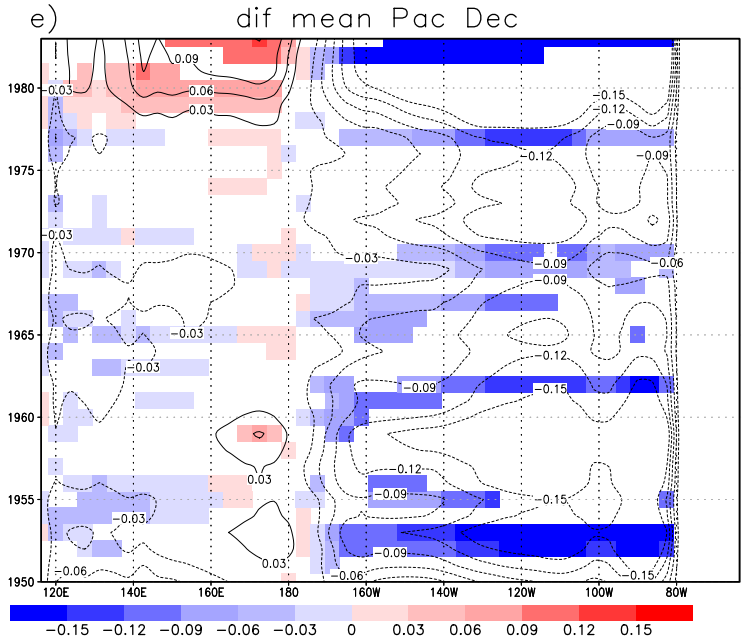

FIG. 3. - (a-b) Differences between mean observed equatorial Atlantic SST from 1950-69 to 1981-2000 in July (left) and December (right, in ${ }^{\circ} \mathrm{C}$ ). (e-f) As (a-b) but for the mean simulated (from SimAtlVar) equatorial Pacific SST; SimAtlCli for the total period are used as a reference value. A t-test of equal means has been applied and significant values at $90 \%$ confidence level are presented. (c-d) Differences between the standard deviation of the equatorial Pacific SST, considering all the members for SimAtlVar, with respect to the standard deviation of the total period from SimAtlCli. A F-test of equal variances has been applied and significant values at $90 \%$ confidence level are shown. The observations come from HadISST1 (Rayner et al. 2003). In order to isolate interannual variations from those of lower frequencies, the difference between the values of each two consecutive years is computed for all data. A colour version of this figure may be found in the online electronic manuscript. 
selected, July and December, according to the maximum variability shown in observations and modelled data (Fig. 2).

A shift in the equatorial Atlantic mean state is observed in July since the late 1960s, so a previous cooling of the Atlantic turns into a warming from the mid1960s. In particular, a significant warming appears in the Atl4 region $\left(40^{\circ} \mathrm{W}-20^{\circ} \mathrm{W}, 3^{\circ} \mathrm{N}-3^{\circ} \mathrm{S}\right)$ since the mid1970s (Fig. 3a), persisting through the seasons (not shown). The modification of the mean state of the eastern equatorial Atlantic is restricted to winter months and only occurs after the 1980s. This result suggests a modification of the western Atlantic SST during summers of the last three decades of the 20th century. The homogeneous warming of the entire equatorial Atlantic in this period has also been reported in previous studies as a reduction of the observed zonal gradient of tropical Atlantic SST (Tokinaga and Xie 2011).

The observed warming of the summer equatorial Atlantic since the 1970s could be affecting the Pacific Ocean, increasing equatorial Pacific variability in the central and eastern part of the basin during summer months (Fig. 3c). The summer Pacific variability forced by the Atlantic could therefore have become higher than the internal variability in the last three decades. Regarding winter months, a constant increase in the Pacific variability is shown during the entire period 1950-2001 (Fig. 3d). Nevertheless, maximum anomalies in the centre and east of the Pacific, similar to the summer pattern (Fig. 3c), are observed since 1970s. Therefore, the Atlantic influence on Pacific variability in summer seems to persist through the seasons. Regarding the Pacific background state, no relevant changes are observed in summer, but an east-west SST gradient following a La Niña-like pattern, with negative anomalies in the centre-east $\left(170^{\circ} \mathrm{W}-80^{\circ} \mathrm{W}\right)$ and positive ones in the west of the basin is observed in winter since the early 1980s (Fig. 3f).

The connection between the interannual processes established since 1970 (Fig. 1) could be related to the change of the Pacific background state in the early 1980s (Fig. 3f). A hypothesis is proposed: a warmer tropical Atlantic could have altered Walker circulation and have linked the Atlantic Niños (Niñas) with the Pacific Niñas (Niños) since the 1970s. Finally, these phenomena could have been gradually modifying the Pacific mean state, becoming statistically significant several years later. This proposed hypothesis will be tested in a future study with sensitivity experiments with partially coupled models considering different background states of the Atlantic.

\section{Modification of the interannual Pacific variability due to the Atlantic influence}

Because the tropical Pacific variability is modified at decadal timescales under an Atlantic forcing, a study of the changes in the interannual variability with and without an Atlantic influence must be considered. To a) corr PC1 SST wind stress z20 JJAS 1950-2001

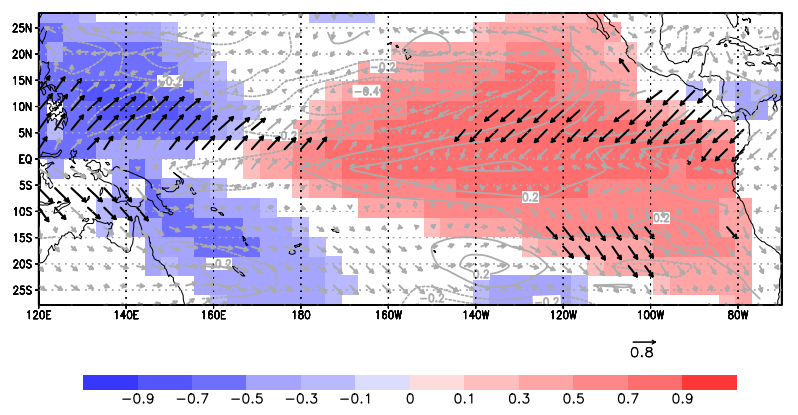

b) corr PC1 SST wind stress z20 JJAS 1950-2001

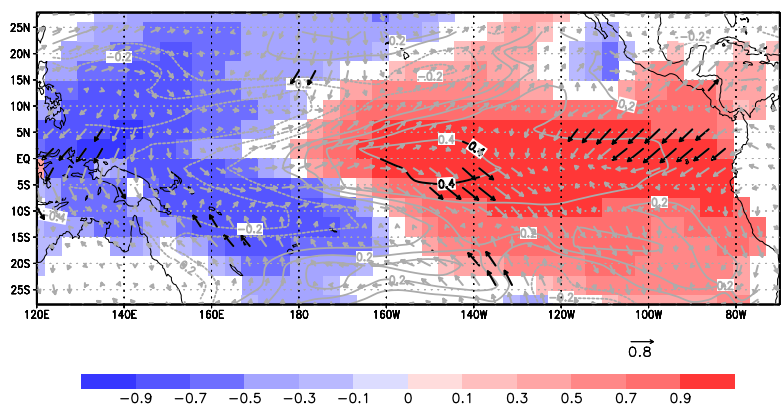

FIG. 4. - (a) Correlation between the first PC of the tropical Pacific SST in DJFM from SimAtlVar and the modelled seasonal SST (shaded), thermocline depth (contour) and windstress (vector) anomalies in the previous summer (JJAS). (b) Same as (a) but for the winter (DJFM). A Monte Carlo test has been applied to obtain significant values at $90 \%$ confidence level. The correlation with thermocline depth is presented in thin contour lines and significant areas are bolded. Only significant areas have been shaded for SST and plotted for vectors. In order to isolate interannual variations from those of lower frequencies, the difference between the values of each two consecutive years is computed for all data. A colour version of this figure may be found in the online electronic manuscript.

this end, an EOF analysis for winter (DJFM) Pacific SST was performed for both SimAtlVar and SimAtlCli SST outputs for the total period of the simulation. Figure 4 presents the corresponding correlation maps for anomalous SSTs, z20 and wind stress in JJAS and DJFM for the tropical Pacific for SimAtlVar (where the Atlantic SSTs are observed).

The leading mode of variability is characterized as an El Niño-like pattern with positive values in the central-east of the basin and a horseshoe-like structure of negative ones in the western Pacific for both SimAtlVar (Fig. 4) and SimAtlCli (not shown). The first mode associated with the Atlantic influence (SimAtlVar) explains $37.7 \%$ of the total variance, whereas the mode associated with the internal variability (SimAtlCli) explains only $35.9 \%$. Thus, the Atlantic Ocean seems to increase the interannual variability of the tropical Pacific in comparison with the internal interannual variability, coherently with the results presented in Figures 2 and 3.

Figure $4(a-b)$ presents the correlation maps of the leading principal component onto SST, thermocline 


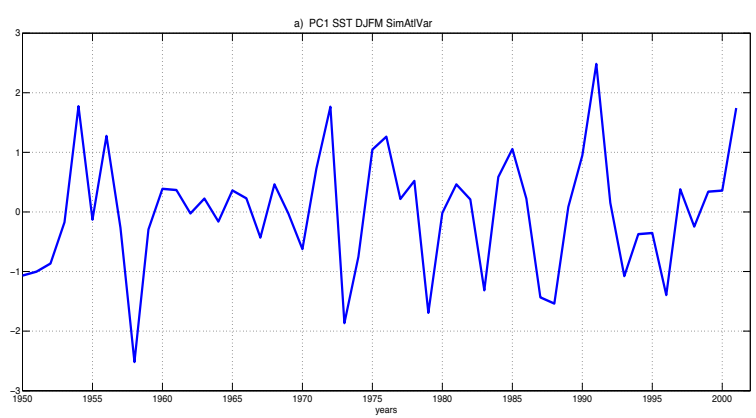

b) Corr PC1-Atl3 PC1-At|4 At|3-At|4 SimAtIVar

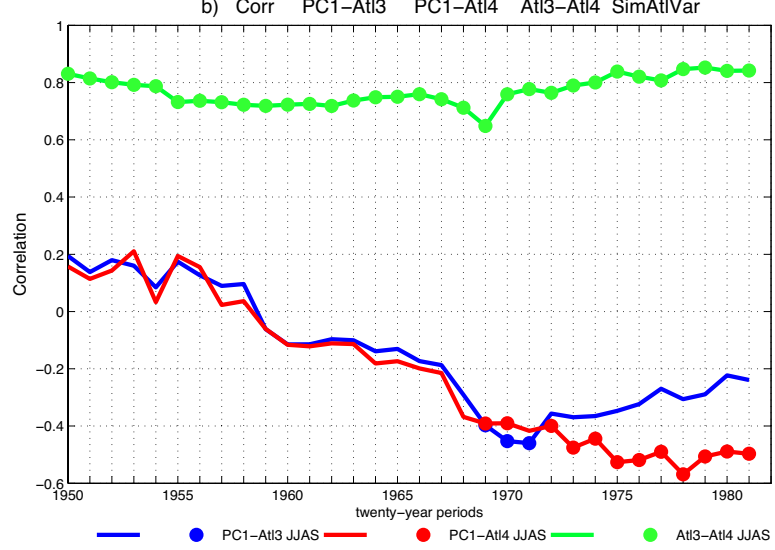

FIG. 5. - (a) Leading PC of the Tropical Pacific SST in DJFM for the period 1950-2001. The nine simulations of SimAtlVar have been used instead of the ensemble mean to compute the PC. It explains $37.7 \%$ of the total variance. (b) Twenty-year correlation between the $\mathrm{PC} 1$ and summer observed At13 index (black line) and At14 index (grey line) in JJAS. Twenty-year correlation between Atl3 and At14 indexes is shown as a light grey line. A Monte Carlo test has been applied and significant values at $90 \%$ confidence level are shown in dots. The observations come from HadISST1 (Rayner et al. 2003). In order to isolate interannual variations from those of lower frequencies, the difference between the values of each two consecutive years is computed for all data. A colour version of this figure may be found in the online electronic manuscript.

depth (z20) and wind stress anomalies for the whole period, considering the simulations with the Atlantic forcing (SimAtlVar). These figures show anomalous winds and warming in the central-east $\left(160^{\circ} \mathrm{W}\right.$ $140^{\circ} \mathrm{W}$ ) of the equatorial Pacific in summer with no significant anomalies in the thermocline depth (Fig. 4a). However, more intense El Niño configuration related to a deeper significant thermocline is observed in winter months (SimAtlVar, Fig. 4b). Thus, the summer anomalous winds could also modify the thermocline depth, triggering the oceanic processes involved in the development of ENSO phenomena during the next few months. It is important to note that the leading mode of variability obtained from $\mathrm{SimAtlCli}$ has no significant signal in z20, which means that less active thermocline feedbacks are involved (not shown). The results presented in Table 1 show how the Atlantic Ocean could favour the creation of less frequent but more intense and dynamic ENSOs, which explain a higher percentage of the Pacific variability (37.7\% versus $35.9 \%$ ).
The results presented in Figure 4 take into account the influence of the Atlantic during the whole period, considering a stationary influence of this basin. However, the observations and Figure 1 show that the Atlantic influence has become significant since the 1970s. In order to study the non-stationarity of this contribution, a 20-year moving correlation between the PC1 (from SimAtlVar) and Atl3 and Atl4 indexes, from 1950-69 to 1981-2000, was calculated (Fig. 5). Significant negative correlations are obtained since the late 1960s and early 1970s for Atl4 and Atl3, respectively. Additional calculations show how these anti-correlations do not depend on the window length (not shown).

It is interesting to note that the correlation values between the Atl3 and Atl4 indexes reach 0.8 in the last three decades. The simultaneous contribution of the Atl3 and Atl4 regions suggests the influence of the entire equatorial Atlantic on the Pacific variability since the 1970s, highlighting the leadership of the western equatorial Atlantic region. Previous studies have already reported the role of anomalous winds in the western equatorial Atlantic in the connection between the Atlantic and Pacific Niños (Münnich and Neelin 2005, Mélice and Servain 2003). However, these authors suggested the influence of ENSO in the creation of anomalous westerlies in the western tropical Atlantic, triggering the eastward propagation of oceanic Kelvin waves responsible for developing the Atlantic Niño. Conversely, the present study points out the leadership of the Atlantic in the connection between these tropical basins, as well as the presence of an equatorial pattern that covers not only Atl3 but also Atl4 (Fig. 5b).

With the aim of understanding the change in the role of the Atlantic SST variability on the Pacific SST interannual leading mode, the correlation of PC1 onto the SST, z20 and wind stress before and after the 1970s is presented in Figure 6. The periods 1950-69 (absence of correlation in Fig. 5) and 1971-90 (significant correlation in Fig. 5) are chosen as reference periods. In Figure $6 \mathrm{c}$ significant wind convergence in the centraleastern Pacific is shown in summer after the 1970s, with a significant signal on z20. In the next winter, significant anomalies of z20 covering the eastern Pacific arise. Therefore, summer anomalous wind could be affecting the ocean surface, perturbing the thermocline depth, triggering active thermocline feedbacks and enhancing the winter SST in the eastern basin (Fig. $6 \mathrm{~d})$. On the other hand, weaker ENSO are shown in the period 1950-69, only characterized by a warming in the eastern Pacific, without modifying wind stress or z20 (Fig. 6a-b). Internal ENSO could be associated with more advective feedbacks according to previous studies (Martín-Rey et al. 2010), while the role of vertical processes in the development of ENSO has been greater in the last two decades, in agreement with other authors (An 2008).

El Niño phenomenon in SimAtlVar before and after the 1970s has also been compared with the variability in the unforced simulation SimAtlClim (not shown). 
a) corr PC1 SST wind stress z20 JJAS 5069

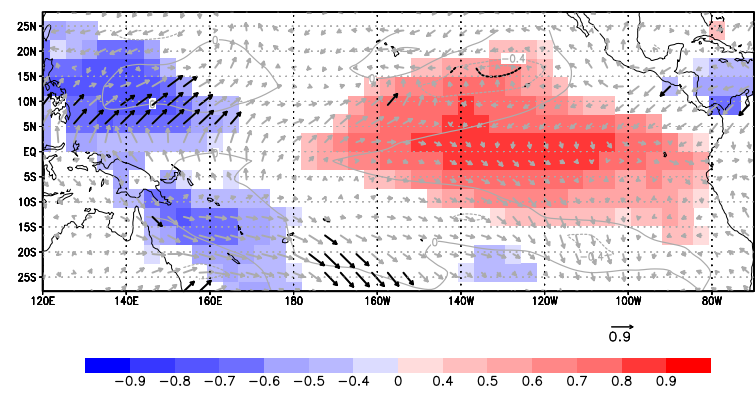

c) corr PC1 SST wind stress z20 JJAS 7190

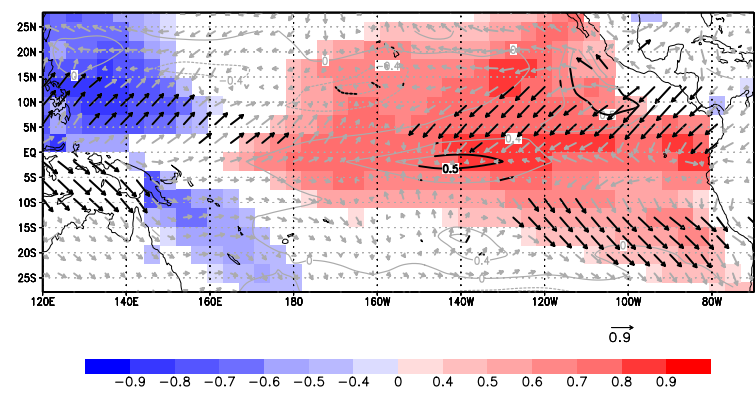

b) corr PC1 SST wind stress z20 DJFM 5069

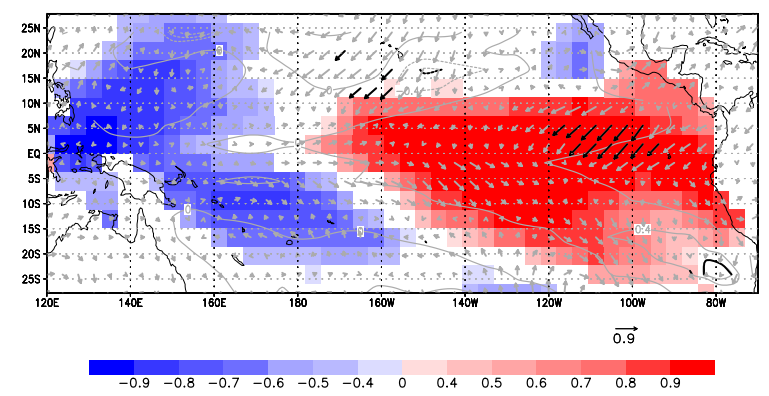

d) corr PC1 SST wind stress z20 DJFM 7190

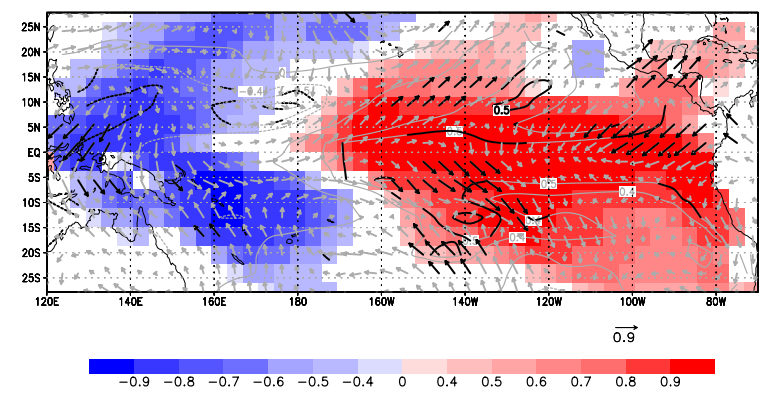

FIG. 6. - Correlation between PC1 of tropical Pacific SST in winter (DJFM) over the modelled seasonal SST (shaded), thermocline depth (contour) and windstress (vector) anomalies in summer (JJAS, left) and winter (DJFM, right) for the periods 1950-69 (top) and 1971-1990 (bottom). A Monte Carlo test has been applied to obtain significant values at $90 \%$ confidence level. The correlation with thermocline depth is presented in thin contour lines and significant areas are bolded. Only significant areas have been shaded for SST and plotted for vectors. In order to isolate interannual variations from those of lower frequencies, the difference between the values of each two consecutive years is computed for all data. A colour version of this figure may be found in the online electronic manuscript.
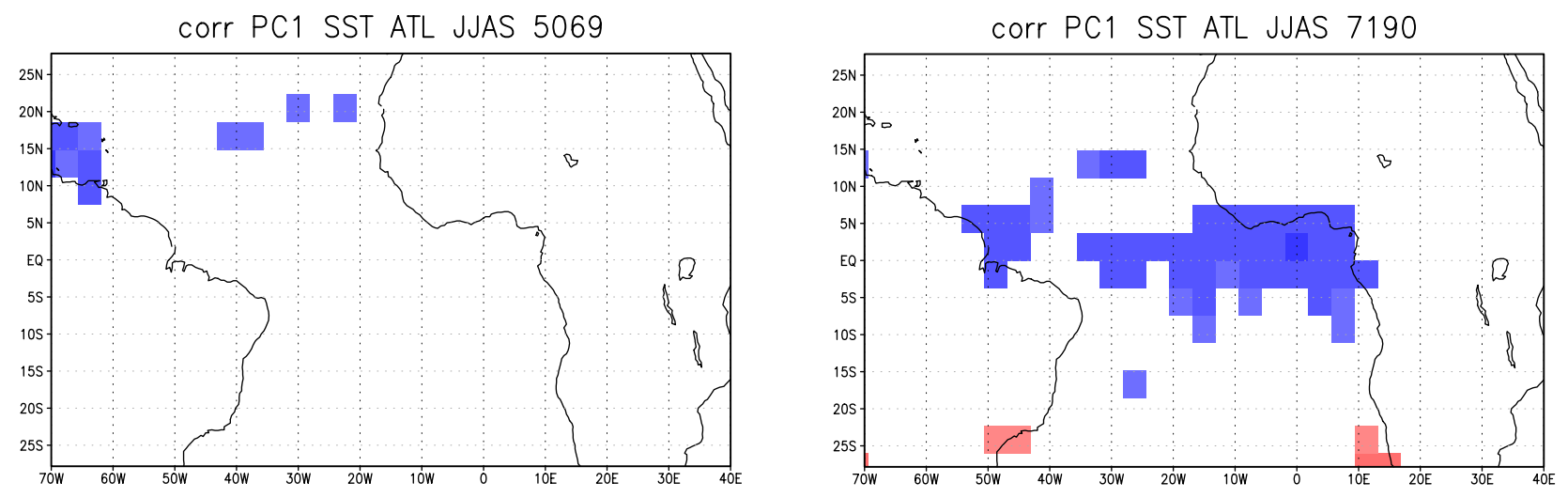

Fig. 7. - Correlation between PC1 of tropical Pacific SST in winter (DJFM) over the observed summer SST for the periods 1950-69 (right) and 1971-1990 (left). A Monte Carlo test has been applied and significant values at $90 \%$ confidence level are shaded. The observations come from HadISST1 (Rayner et al. 2003). In order to isolate interannual variations from those of lower frequencies, the difference between the values of each two consecutive years is computed for all data. A colour version of this figure may be found in the online electronic manuscript.

The difference between these patterns highlights the important role played by wind stress in the tropical Pacific in summer, creating a perturbation in thermocline depth that alters the dynamic ocean processes involved in the ENSO development.

In order to determine the Atlantic pattern affecting the leading equatorial Pacific variability mode after the 1970s, the regression of the first PC1 onto the observed Atlantic SST during the previous summer is shown in Figure 7. For the positive phase of the Pacific leading
EOF, an equatorial cooling that covers not only the eastern but also the western side of the Atlantic basin is observed since 1970, but not in previous decades (Fig. 7a-b), confirming the anti-correlation found in Rodríguez-Fonseca et al. (2009) and later in Ding et al. (2011).

This result indicates that the Atlantic has been able to modify the main variability modes of the tropical Pacific since the 1970s, so that an anomalous cooling over the equatorial Atlantic is related to a warming of the equatorial and eastern Pacific. The mechanism 
TABLE 1. - Statistical analysis of the ENSO phenomena from Principal Components created from SimAtlVar (all the 9 members are considered) for the total periods 1950-69 (P1) and 1971-90 (P2) and from SimVarClim (all the 5 members are considered).

\begin{tabular}{|c|c|c|c|c|c|}
\hline & P1 & $\begin{array}{c}\text { SimAtlVar } \\
(9 \text { members }) \\
\text { P2 }\end{array}$ & 1950-2001 & $\begin{array}{l}\text { SimAtlCli } \\
\text { (5 members) } \\
130 \text { years }\end{array}$ & Forced simulation vs control \\
\hline Ratio Niños/Niñas & 0.88 & 0.95 & 0.97 & 1.06 & Increase of Niñas \\
\hline Ratio EP/CP & 6.25 & 3.11 & 3.81 & 4.01 & Increase of CP \\
\hline Skewness & 0.33 & -0.019 & 0.01 & 0.25 & Increase of symmetry \\
\hline Related to TA & & Atl3-Atl4 & At14 & No related & Atl-Pac connection \\
\hline Variance explained (DJFM) & & & $37.7 \%$ & $35.9 \%$ & Increase variability specially DJFM \\
\hline Periodicity (from peaks of power spectrum) & & & $\begin{array}{l}{\left[\begin{array}{ll}6 & 8\end{array}\right] \text { years }} \\
{[4-5] \text { years }}\end{array}$ & $\begin{array}{c}{[6 \text { 7] years }} \\
3.5 ; 5.5 \text { years }\end{array}$ & $\begin{array}{l}\text { Increase periodicity in } 4-5 \text { years } \\
\text { band }\end{array}$ \\
\hline
\end{tabular}

involves anomalous winds in the central Pacific during the summer, and a modification of the thermocline depth in this region. This perturbation could propagate eastward, creating more intense ENSOs in the last three decades. This is in agreement with the more active dynamic feedbacks since the 1970s from an Atlantic forcing (Martín-Rey et al. 2010).

\section{Classification of ENSO events}

The CP and EP phenomena generated by the model (from SimAtlVar and SimAtlCli) are analogous to those shown in observations (Kao and Yu 2009, Kug et al. 2009, Lee and McPhaden 2010). The CP Niños (Niñas) have a dipolar structure formed by positive (negative) anomalies in the central-eastern $\left(120^{\circ} \mathrm{W}-180^{\circ} \mathrm{W}\right)$ and negative (positive) ones in the western equatorial $\mathrm{Pa}$ cific (not shown). The maximum central SST anomaly is restricted to the equatorial band, reaching the dateline. On the other hand, EP ENSOs are similar to CP ones, but the maximum SST anomalies are placed in the eastern Pacific $\left(150^{\circ} \mathrm{W}-100^{\circ} \mathrm{W}\right)$.

Although modelled Niños are mainly EP (more than 70\%), the ratio between EP and CP events is slightly reduced in SimAtlVar (Table 1), suggesting an increase in CP ENSOs due to the Atlantic influence. Regarding the ENSO phase, an increase in the occurrence of La Niña phenomenon is also observed in SimAtlVar. The tropical Atlantic Ocean therefore seems to favour the negative phase of ENSOs. Furthermore, the internal variability shows a strong asymmetry of ENSO events with a stronger positive phase of ENSO, skewness 0.25 in the SimAtlCli versus 0.01 in the SimAtlVar. Atlantic forcing seems to rectify this bias of the internal variability by given more weight to La Niña events.

In order to study the modification of the ENSO phenomena due to the Atlantic contribution, a statistical analysis of the interannual processes of the tropical Pacific was performed in the selected periods, 195069 and 1971-90 (from SimAtlVar). The ENSO events were identified and classified according to their positive (El Niño) or negative (La Niña) phase and their type (CP or EP, Table 1). An increase in the number of events is shown after the 1970s, most of all in the positive phase, so the ratio between Niños and Niñas is close to 1. The number of CP ENSOs has doubled since 1970. This increase in CP events has been also reported in previous studies (Ashok et al. 2007, Yeh et al. 2009, Lee and McPhaden 2010) but the causes of this change are still unresolved. Yeh et al. (2009) suggest the contribution of anthropogenic forcing in favouring CP ENSOs. Finally, decadal and multidecadal variability could also play an important role in the type of ENSO phenomena (McPhaden and Zhang 2002, Lee and McPhaden 2008, Yu et al. 2010, Yeh et al. 2011).

\section{DISCUSSION AND CONCLUSIONS}

This paper analyses the changes in the mean state, variability and modes of variability in the tropical Pacific, using a coupled simulation with the observed SST in the Atlantic as external forcing, as in Rodríguez-Fonseca et al. (2009). This analysis shows that the connection established between the Atlantic Niños (Niñas) and the Pacific Niñas (Niños) since the early 1970s may have contributed not only to the interannual events but also to the change in the Pacific variability and background state in the last three decades.

This study uses different simulations in order to address different features not shown in RodríguezFonseca et al. (2009): 1) the SimAtlVar simulation in comparison with the SimAtlCli control simulation demonstrates the clear influence of the Atlantic on the Pacific; and 2) the differences between the same SimAtlVar simulation for the period before the 1970s and after the 1970s demonstrate that the AtlanticPacific connection is non-stationary and thermocline feedbacks have been more active in the Pacific El Niño development in the last three decades.

On the basis of these results, a preliminary hypothesis is posed: a warmer Atlantic could have altered the Walker circulation, linking the two tropical oceans since the late 1960 s, increasing Pacific variability and connecting the interannual events of the two basins. Because of the Atlantic contribution, these ENSO phenomena could have gradually changed the Pacific background state, highlighting a significant cooling since the late 1970s. However, to test this hypothesis, partially coupled simulations are needed.

The Tropical Pacific SST variability shows an El Niño-like leading pattern, significantly anti-correlated with the Atl4 and Atl3 indexes since the late 1960s and early 1970s, respectively. The significant correlation between Atl4 and $\mathrm{PC} 1$ suggests that the western 
a)

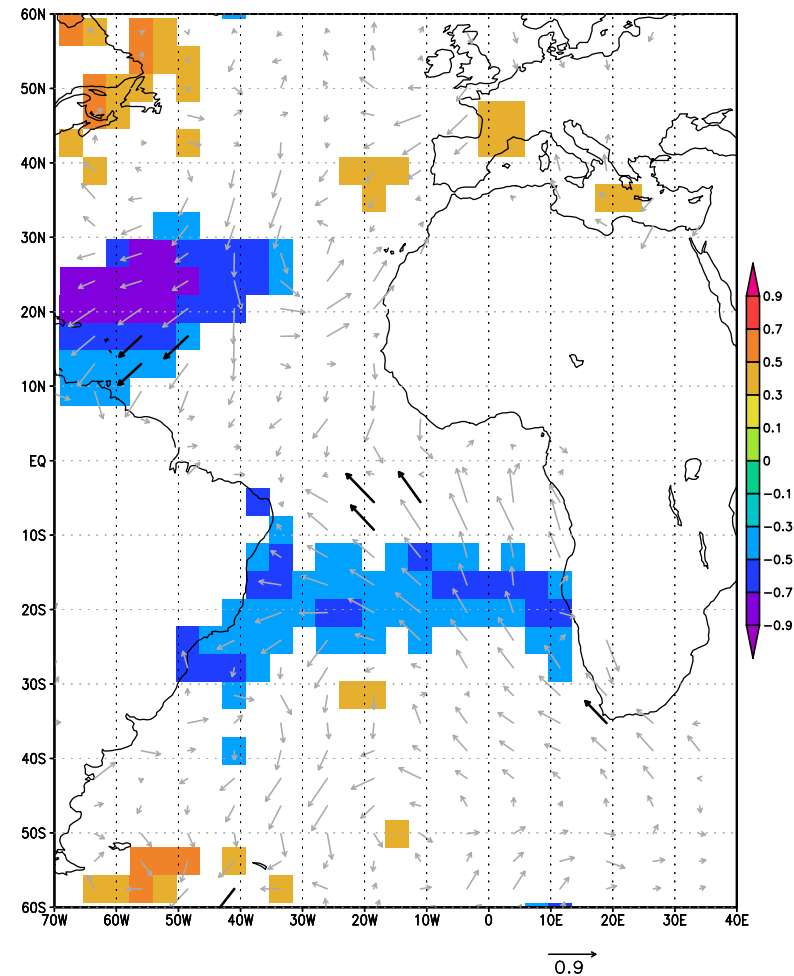

c)

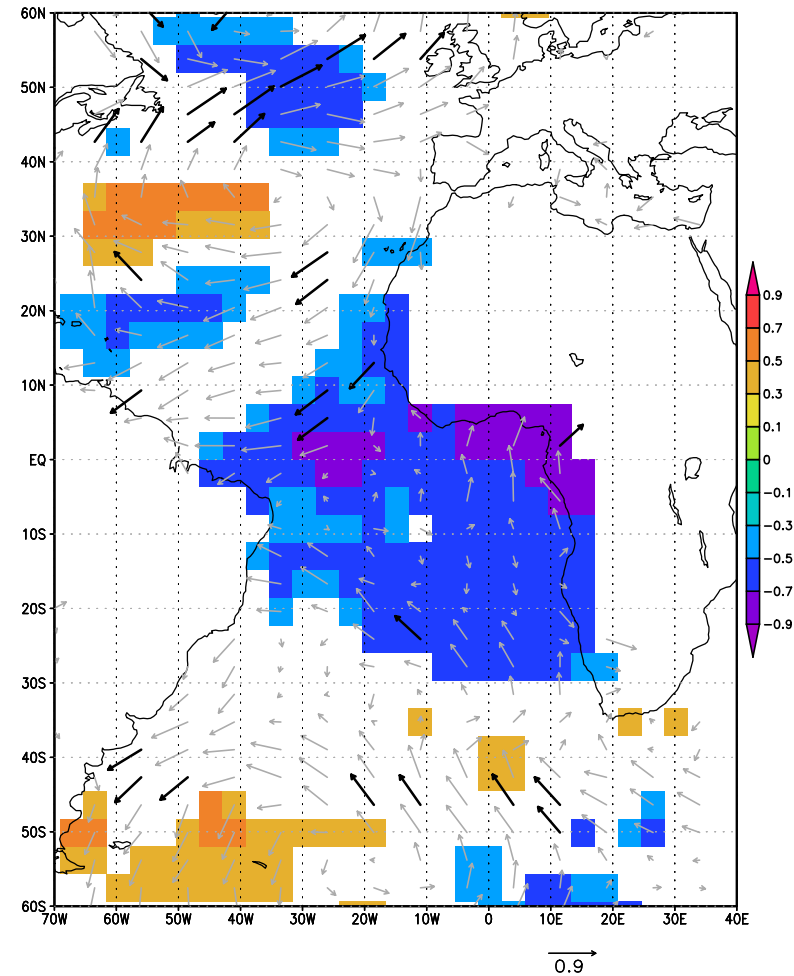

b) JFMA O

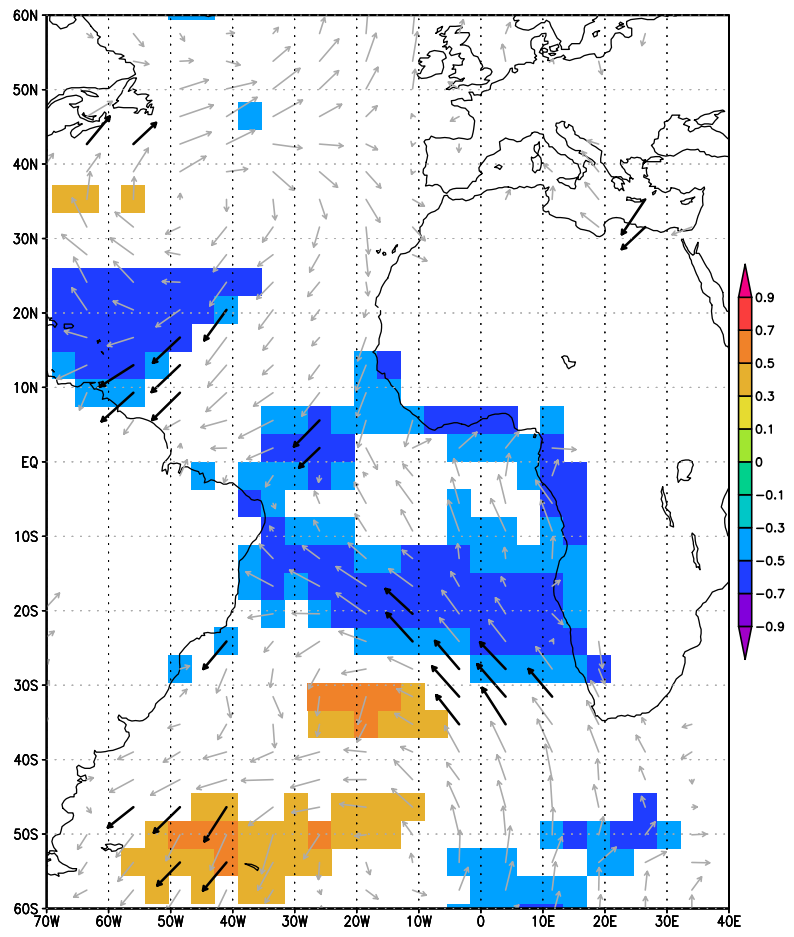

d)

JJAS 0

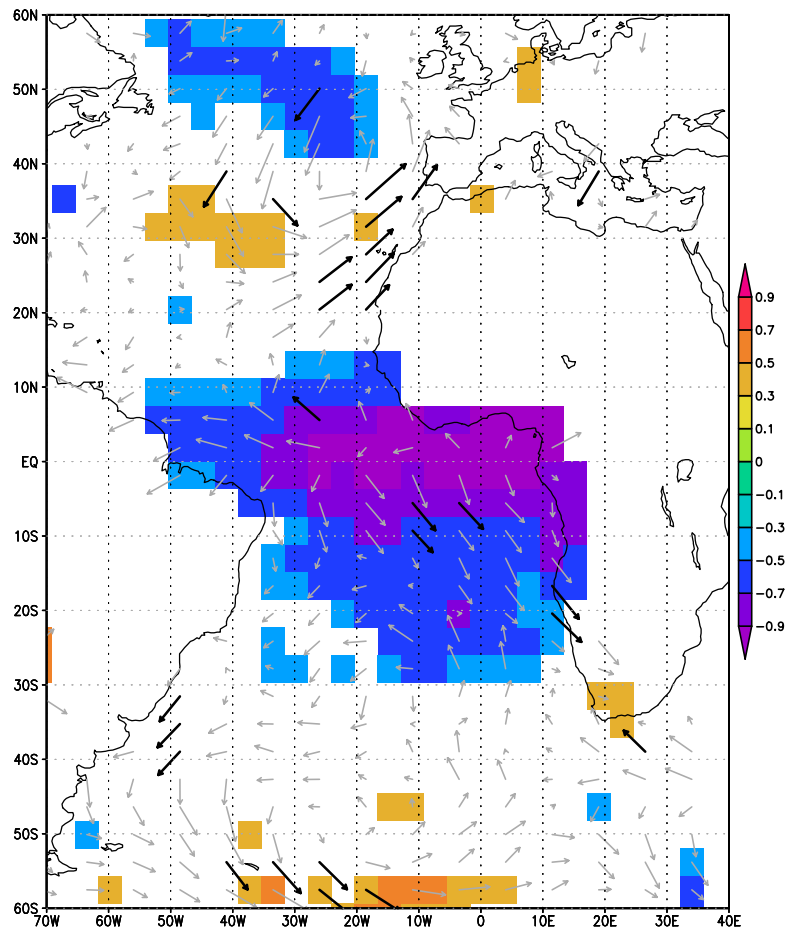

$\overrightarrow{0.9}$

FIG. 8. - Correlation between the time series of the summer (JJAS) equatorial Atlantic SST pattern (where the time series has been calculated by regressing the SST pattern from Figure 6c map over the time-space matrix of anomalous SST in JJAS in the equatorial Atlantic) and the observed anomalous SST (multiplied by -1 for consistency with the rest of the article) and wind stress from NDJF (year -1) to JJAS (year 0) in the Atlantic Ocean for the period 1971-90. A Monte Carlo test has been applied and significant values at $90 \%$ confidence level are shown in shaded (SST) and black vectors (wind stress). The observations come from HadISST1 (Rayner et al. 2003). In order to isolate interannual variations from those of lower frequencies, the difference between the values of each two consecutive years is computed for all data. A colour version of this figure may be found in the online electronic manuscript. 
tropical Atlantic has played a determinant role in the inter-basin connection in recent decades. The simultaneous contribution of the Atl3 and Atl4 indexes in Pacific variability since the 1970 s suggests that the entire equatorial band in the Atlantic Ocean must have been involved.

The understanding of the origin and development of the Atlantic SST pattern related to the ENSO mode since the 1970s is beyond the scope of this study and will be the aim of a future one. However, here we present a preliminary attempt to discern the observed wind stress and SST anomalous patterns over the tropical Atlantic that can force El Niño during the following winter in the last few decades (Fig. 8). Anomalous easterly winds south of the equator $\left(10^{\circ} \mathrm{S}-20^{\circ} \mathrm{S}\right)$, associated with a strengthening of the St. Helena High (Figure $8 \mathrm{a})$, could favour the upwelling in the Benguela area, cooling this region in the following months (Fig. 8b). On the other hand, the subtropical high in the North Atlantic seems to also be altered in spring, contributing to the cooling of the western and northern tropical Atlantic (Fig. 8c). The contribution of the St. Helena Subtropical High was studied previously in Lübbecke et al. (2010) and Richter et al. (2010), but these authors did not deal with the contribution of the Azores High, which is a novelty of this work and requires further analysis. The alteration of the St. Helena High seems to favour the development of the SST anomalies in the eastern Atlantic (Lübbecke et al. 2010, Richter et al. 2010), but the Atlantic SST pattern related to Pacific Niños since the 1970s shows a westward extension (Fig. 8d) that could be due to the additional contribution of the Azores High. Finally, an equatorial SST pattern covering the entire equatorial basin $\left(60^{\circ} \mathrm{W}\right.$ $\left.10^{\circ} \mathrm{E}, 10^{\circ} \mathrm{N}-30^{\circ} \mathrm{S}\right)$ is developed. This result suggests the possible contribution of the subtropical highs of both hemispheres in the development of Atlantic Niños since the 1970s.

The correlation patterns of the PCs before and after the 1970s show anomalous cooling in the equatorial Atlantic associated with anomalous winds over the central tropical Pacific in summer months. These wind anomalies could also create a perturbation in z20 in the central Pacific, propagating eastward and generating more intense ENSO phenomena since the 1970s. The Atlantic thus seems to alter the dynamic processes associated with the development of ENSO in the last decades. This result agrees with Martín-Rey et al. (2010), who suggest the important role of the vertical processes in the creation of ENSO events in the last few decades from an Atlantic forcing. However, further analysis of the changes in the oceanic processes due to the Atlantic contribution before and after the 1970s are needed.

The Atlantic forcing is able to explain some of the recent changes in the ENSO variability since the 1970s, such as the increase in the intensity of the events, the increase in CP Niños, the increase in frequency in the band of $1 /[4-5]$ years $^{-1}$, and more active thermocline feedbacks. However, it fails to explain the great asym- metry of Niños since the 1970s, which has been related to more non-linear processes and stronger thermocline feedbacks (An 2008). This failure could be due to some limitation in the coupled model but more research into the sources of decadal variability of ENSO phenomena is also needed.

All these changes (summarized in Table 1) suggest that the Atlantic mean state and its associated interannual variability make an important contribution to understanding the recent changes over the tropical Pacific basin in last decades. Further research is necessary to understand the development of Atlantic Niños since the 1970s, in order to determine the causes of the Atlantic-Pacific connection established in the last few decades.

\section{ACKNOWLEDGEMENTS}

This study was supported through the Spanish MICINN projects TRACS (CGL2009-10285) and MOVAC (ref. 200800050084028). We would like to thank the anonymous reviewers, in particular reviewer 3, for their useful comments, which helped to improve the manuscript. Also, we would like to thank Alan Lounds for his corrections and suggestions in the English revision. We are very grateful to the editor for making very encouraging and helpful suggestions and helping in the whole process.

\section{REFERENCES}

An S.I. and Wang B. 2000. Interdecadal change of the structure of the ENSO mode and its impact on the ENSO frequency. J. Clim. 13: 2044-2055.

An S.I. 2008. A review of interdecadal changes in the nonlinearity of the El Niño-Southern Oscillation. Theor. Appl. Climatol. 97: 29-40.

Ashok K., Behera S.K., Rao S. A., Weng H., Yamagata T. 2007. El Niño Modoki and its possible teleconnections. J. Geophys. Res. 112: C11007.

Bjerknes J. 1964. Atlantic air-sea interaction. Adv. Geophys. 10: $10-82$.

Bjerknes J. 1969. Atmospheric teleconnections from the equatorial Pacific. Mon. Weather Rev. 97: 163-72.

Carton J.A., Chepurin G., Cao X.H., Giese B.S. 2000. A Simple Ocean Data Assimilation analysis of the global upper ocean 1950-95. Part I: Methodology. J. Phys. Oceanogr. 30: 294-309.

Chang P. 1994. A study of the seasonal cycle of sea surface temperature in the tropical Pacific Ocean using reduced gravity models. J. Geophys. Res. 99: 7725-7741.

Chang P., Fang Y., Saravannan R., Ji L., Seidel H. 2006. The cause of the fragile relationship between the Pacific El Niño and the Atlantic Niño. Nature 443: 324-328.

Chiang J.C.H., Kushnir Y. 2000. Interdecadal changes in the eastern Pacific ITCZ variability and its influence on the Atlantic ICTZ. Geophys. Res. Lett. 27: 3687-3690.

Choi J., An S., Kug J.-S., Yeh S.W. 2010. The role of mean state on changes in El Niño's flavor. Clim. Dyn. 37: 1205-1215.

Ding H., Keenlyside N.S., Latif M. 2011. Impact of the Equatorial Atlantic on the El Niño Southern Oscillation. Clim. Dyn. doi: 10.1007/s00382-011-1097-y.

Dommenget D., Semenov V., Latif M. 2006. Impacts of the tropical Indian and Atlantic Oceans on ENSO. Geophys. Res. Lett. 33: L11701.

Dong B., Sutton R.T., Scaife A.A. 2006. Multidecadal modulation of el Niño-Southern Oscillation (ENSO) variance by Atlantic Ocean sea surface temperatures. Geophys. Res. Lett. 33: L08705. 
Federov A., Philander S.G. 2000. Is El Niño changing? Science 288: 1997-2002.

García-Serrano J., Losada T., Rodríguez-Fonseca B., Polo I. 2008. Tropical Atlantic variability modes (1979-2002). Part II: Timeevolving atmospheric circulation related to SST-forced tropical convection. J. Clim. 21: 6476-6497.

Kao H.-Y., Yu J.-Y. 2009. Contrasting Eastern-Pacific and CentralPacific Types of ENSO. J. Clim. 22: 616-632.

Keenlyside N.S., Latif M. 2007. Understanding Equatorial Atlantic interannual variability. J. Clim. 30: 131-142.

Kucharski, F., Bracco A., Yoo J.H., Molteni F. 2008. Atlantic forced component of the Indian monsoon interannual variability. Geophys. Res. Lett. 35: L04706.

Kucharski F., Kang I.-S., Farneti R., Feudale L. 2011. Tropical Pacific response to $20^{\text {th }}$ Century Atlantic Warming. Geophys. Res. Lett. 38: L03702.

Kug J.-S., Jin F.F., An S.I. 2009. Two types of El Niño Events: Cold tongue El Niño and Warm Pool El Niño. J. Clim. 22: 615-636.

Izumo T., Vilard J., Lengaigne M., Montegut C.D.B., Behera S.K., Luo J.J., Cravatte S., Masson S., Yamagata T. 2010. Influence of the state of the Indian Ocean dipole of the following year's El Niño. Nature 3: 168-172.

Lee T., McPhaden M.J. 2010. Increasing intensity of El Niño in the central-equatorial Pacific. Geophys. Res. Lett. 37: L14603.

Lee T., McPhaden M.J. 2008. Decadal phase change in large-scale sea level and winds in the Indo Pacific region at the end of the $20^{\text {th }}$ century. Geophys. Res. Lett. 35: L01605.

Lin P.-F., Liu H.-L., Li C., Zhang X.-H. 2010. Spring Cold Bias of SST and Minimal Wind Mixing in the Equatorial Pacific Cold Tongue. Atmos. Oceanic. Sci. Lett. 3: 342-346.

López-Parages J., Rodríguez-Fonseca B. 2012. Multidecadal Modulation of El Niño influence on the Euro-Mediterranean rainfall. Geophys. Res. Lett. 39: L02704.

Losada T., Rodríguez-Fonseca B., Janicot S., Gervois S., Chauvin F., Ruti P. 2010a. A multimodel approach to the Atlantic equatorial mode. Impact on the West African monsoon. Clim. Dyn. 35: $29-43$.

Losada T., Rodríguez-Fonseca B., Polo I., Janicot S., Gervois S., Chauvin F., Ruti P. 2010b. Tropical response to the Atlantic Equatorial mode: AGCM multimodel approach. Clim. Dyn. 5: 45-52.

Lübbecke J.F., Böning C.W., Keenlyside N.S., Xie S. 2010. On the connection between Benguela and equatorial Atlantic Niños and the role of the South Atlantic Anticyclone. J. Geophys. Res. 115: C09015.

Martín-Rey M. 2010. Estudio del océano superior del Pacífico Tropical y su relación con un forzamiento del Atlántico. Master Thesis, Universidad Complutense de Madrid.

McPhaden M.J., Zhang D. 2002. Slowdown of the meridional overturning circulation in the upper Pacific Ocean. Nature 415: 603-608.

Mechoso C.R., Robertson A.W., Barth N., Davey M.K., Delecluse P., Gent P.R., Ineson S., Kirtman B., Latif M., Le Treut H., Nagai T., Neelin J.D., Philander S.G.H., Polcher J., Schopf P.S., Stockdale T., Suarez M.J., Terray L., Thual O., Tribbia J.J. 1995. The seasonal cycle over the Tropical Pacific in Coupled Ocean-Atmosphere General Circulation Models. Mon. Weather Rev. 123: 2825-2838.

Melice J.L., Servain J. 2003. The tropical Atlantic meridional SST gradient index and its relationships with the SOI, NAO and Southern Ocean. Clim. Dyn. 20: 447-464.
Moon B.K, Yeh S.W., Dewitte B., Jhun J.G., Kang I.S., Kirtman B.P. 2004. Vertical structure variability in the equatorial Pacific before and after the Pacific climate shift of the 1970s. Geophys. Res. Lett. 31: L03203.

Münnich M., Neelin J. D. 2005. Seasonal influence of ENSO on the Atlantic ITCZ and equatorial South America. Geophys. Res. Lett. 32: L21709.

Philander S.G. 1990. El Niño, La Nina, and the Southern Oscillation. Academic Press, San Diego, 293 pp.

Polo I., Rodríguez-Fonseca B., Losada T., García-Serrano J. 2008. Tropical Atlantic variability modes (1979-2002). Part I: Timeevolving SST modes related to West African rainfall. J. Clim. 21: 6457-6475.

Rayner, N.A., Parker D.E., Horton E.B., Folland C.K., Alexander L.V., Rowell D.P., Kent E.C., Kaplan A. 2003. Globally complete analyses of sea surface temperature, sea ice and night marine air temperature, 1871-2000. J. Geophys. Res. 108, 4407.

Richter I., Behera S., Masumoto Y., Taguchi B., Komori N., Yamagata T. 2010. On the triggering of Benguela Niños: Remote equatorial versus local influences, Geophys. Res. Lett. 37: L20604.

Rodríguez-Fonseca B., Polo I., García-Serrano J., Losada T., Mohino E., Mechoso C.R., Kucharski F. 2009. Are Atlantic Niños enhancing Pacific ENSO events in recent decades? Geophys. Res. Lett. 36: L20705.

Stephenson D.B., Pavan V., Bojariu R. 2000. Is the North Atlantic oscillation a random walk? Int. J. Climatol. 20: 1-18.

Sutton R.T., Hodson D.L.R. 2007. Climate Response to BasinScale Warming and Cooling of the North Atlantic Ocean. J. Clim. 20: 891-907.

Tokinaga H., Xie S.P. 2011. Weakening of the equatorial Atlantic cold tongue over the past six decades. Nature Geosci. 4: 222-226.

Von Storch H., Frankignoul C. 1998. Empirical Modal Decomposition in coastal oceanography. In: Brink K.H., Robinson A.R. (eds.) The Sea: Vol. 10, the Global Coastal Ocean. John Wiley, p. 419-455.

Wang C. 2006. An overlooked feature of tropical climate: InterPacific-Atlantic variability. Geophys. Res. Lett. 33: L12702.

Wang C.S., Lee K., Mechoso C.R. 2010. Interhemispheric Influence of the Atlantic Warm Pool on the Southeastern Pacific. J. Clim. 23: 404-418.

Xie S.-P. 1994. On the genesis of the equatorial annual cycle. J.Clim. 7: 2008-2013.

Yeh S.-W., Kirtman B. Kug J-S, Park W., Latif M. 2011. Natural variability of the central Pacific El Niño event on multi-centennial timescales. Geophys. Res. Lett. 38: L15709.

Yeh S.-W., Kug J.-S., Dewitte B., Kwon M.-H., Kirtman B., Jin F.-F. 2009. Recent changes in El Niño and its projection under global warming. Nature 461: 511-515.

Yu J.-Y., Kao H.-Y., Lee T. 2010. Subtropics-related interannual sea surface temperature variability in the central Equatorial Pacific. J. Clim. 23: 2869-2884.

Zebiak S.E. 1993. Air-sea interaction in the equatorial Atlantic region. J. Clim. 6: 1567-1586.

Zhao M., Wang G., Hendon H.H., Alves O. 2011. Impact of including surface currents on simulation of Indian Ocean variability with the POAMA coupled model. Clim. Dyn. 36: 1291-1302.

Received March 4, 2011. Accepted January 27, 2012.

Published online August 5, 2012. 